Case 7, Dr. Griffith.-A woman aged 38. Fissures at the corners of the mouth; smooth tongue; conjunctiva and mucous membrane of mouth pallid. The patient had lived in Australia for a number of years, and had received X-ray treatment for the fissures.

Dr. Bellringer mentioned that fissuring at the angles of the mouth was commonly seen in women in New Zealand in association with various types of anæmia, both primary and secondary, although it was also found in the absence of anæmia. $\mathrm{He}$ thought the immediate cause was due to streptococcal invasion of the weakened tissues, or spread of general reaction from the mouth. It was of value in this case to estimate the hæmoglobin of the blood, and if the latter was below 75 per cent., a blood count should be done. Looking through his figures of idiopathic hypochromic anæmia, he found that 85 per cent. of these cases showed either achlorhydria or hypochlorhydria. With regard to general treatment, he advised, in addition to massive doses of iron, a minute amount of copper sulphate (grains 1/16th to grains $1 / 12$ th to the dose). Vitamin in the form of brewer's yeast or marmite was also of value.

Case 8, Dr. Griffith.-A patient, male, aged 40 , with a pustular dermatitis of five months' duration, affecting both hands. Dr. Griffith suggested the diagnosis of pustular psoriasis.

Dr. Wigley thought it was probably a case of an external dermatitis due to sugar soap or some other similar substance.

\title{
REVIEWS.
}

\section{THE SCIENCE OF SIGNS AND SYMPTOMS.}

By Prof. R. J. S. McDowall. 3rd Edition. Messrs. William Heinemann. 1934. 21/-.

It is a healthy sign that this work should have passed through three editions within the space of a little more than two years, for it shows the demand that prevails for a thorough understanding of the rationale of the signs and symptoms of disease. Symptomatology, and under this term the author includes both subjective and objective evidence of disease, is discussed by Prof. McDowall in a most interesting and comprehensive manner and is explained in as far as is possible on a physiological, or perhaps more correctly, a biological basis. It is this wide outlook on the problems of disease with the soundness of the conclusions drawn which makes this book one which can be constantly referred to with profit by all students of medicine.

\section{WHAT OF THE CHILD?}

By Andrew Kefalas, M.A., M.B., Ch.B. William Heinemann, Ltd.

Price, 5/-.

There is always room for sincerity and simplicity even in the somewhat overloaded literature of ohild welfare and education, so we may unhesitatingly welcome this little book which is well within the scope of the average intelligence and the average purse. The author, in a small volume of 180 pages, gives advice on the physical, mental and moral rearing of children, salted with a fair amount of prejudice and dogmatism, but not by any means without humour and common sense. Experienced parents and teachers will agree with many of his dicta, and equally heartily disagree with others. If only the questions that children asked were all as tactful as he suggests! After all, the problem of where the kittens come from is simple enough and raises no blush to the cheek of the modern parent, but what of the small and perfectly serious boy who says to his mother (in front of strangers at lunch) "But how do you know that Father is my father?" 